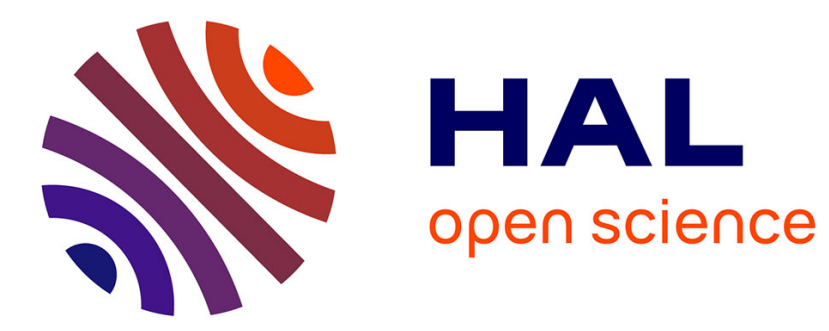

\title{
On the comparison of pseudo-first order and pseudo-second order rate laws in the modeling of adsorption kinetics \\ Jean-Pierre Simonin
}

\section{- To cite this version:}

Jean-Pierre Simonin. On the comparison of pseudo-first order and pseudo-second order rate laws in the modeling of adsorption kinetics. Journal Chemical Engineering, 2016, 10.1016/j.cej.2016.04.079 . hal-01311325

\section{HAL Id: hal-01311325 \\ https: / hal.sorbonne-universite.fr/hal-01311325}

Submitted on 4 May 2016

HAL is a multi-disciplinary open access archive for the deposit and dissemination of scientific research documents, whether they are published or not. The documents may come from teaching and research institutions in France or abroad, or from public or private research centers.
L'archive ouverte pluridisciplinaire HAL, est destinée au dépôt et à la diffusion de documents scientifiques de niveau recherche, publiés ou non, émanant des établissements d'enseignement et de recherche français ou étrangers, des laboratoires publics ou privés. 


\title{
On the comparison of pseudo-first order and pseudo-second order rate laws in the modeling of adsorption kinetics
}

\author{
Jean-Pierre Simonin ${ }^{\mathrm{a}, \mathrm{b}}$ \\ ${ }^{a}$ CNRS, UMR 8234, PHENIX, F-75005, Paris, France. \\ ${ }^{b}$ Laboratoire PHENIX, Sorbonne Universités, UPMC Univ Paris 06, UMR 8234, Université P.M. \\ Curie, F-75005, Paris, France
}

\begin{abstract}
In most works in the current literature about liquid/solid adsorption kinetics, the respective abilities of pseudo-first order and pseudo-second kinetics for describing the data are compared. In nearly all cases, it is concluded that the latter surpasses the former. The aim of this work is to point out that more caution should be exercised in this comparison. Indeed, it appears that the method generally used is flawed and that it unfairly favors pseudo-second order kinetics. A different method is proposed to analyze experimental results. It is employed here to reexamine experimental data taken from the literature.
\end{abstract}

Keywords: Adsorption; Kinetics; Pseudo-first order; Pseudo-second order.

\section{Introduction}

Adsorption by various materials is often studied as a potential tool for the purification of water and industrial effluents. In general, works in this field report experimental results about the adsorption capacity of solutes at equilibrium, and about the kinetics of adsorption. The data are then described using various models or empirical formulas.

In the literature, two types of equations have been commonly used to represent the kinetics. The first one, which corresponds to a diffusion-controlled process, is the intraparticle diffusion equation $[1,2,3,4,5]$, together with more elaborate treatments proposed recently [6]. The second one assumes that the process is controlled by the adsorption reaction at the liquid/solid interface in the adsorbent. An excellent review about slow adsorption (and desorption) is available in the literature [7].

Two types of kinetics are generally used and compared, namely the pseudo-first order and pseudo-second order rate laws. Pseudo-first order kinetics (hereafter denoted by $\mathrm{K}^{1}$ ) was first proposed at the end of the 19th century by Lagergren [8]. Pseudo-second order kinetics (denoted by K2 ${ }^{2}$ ) was introduced in the middle of the 80's $[9,10]$. However it was not very popular until 1999 when Ho and McKay [11] analyzed a number of experimental results taken from the literature, and arrived at the conclusion that, "for all of the systems studied, $[\ldots]$ the pseudo-second order reaction kinetics provide the best correlation of the experimental data". After publication of this work, K2 has become increasingly popular because, in the vast majority of studies in which comparison has been done, superiority of

\footnotetext{
Email address: jpsimonin@gmail.com. Tel. +33 144273190; Fax +33 144273228. (Jean-Pierre Simonin)

${ }^{1} \mathrm{~K} 1$ : pseudo-first order kinetics

${ }^{2} \mathrm{~K} 2$ : pseudo-second order kinetics
} 
K2 over K1 has been found [12]. The original article [11] now totalizes ca. 6000 citations, with a citation frequency that has been increasing exponentially with time.

The purpose of the present work is to point out the fact that more caution should be exercised in the analysis of kinetic data. It is shown below that there are two main issues in the statistical treatment generally used in the literature, and that this method systematically tends to favor the pseudo-second order rate law.

The remainder of this paper is divided into three main sections. In the next section, the basic formulas for the statistical analysis of experimental data and model comparison are presented. The third section is dedicated to the presentation of results and to their discussion. The two issues met in analyses used in the literature are exposed and they are illustrated in the case of data obeying first order kinetics. Then a reexamination of the experimental data treated in the original paper by Ho and McKay [11] is carried out, a sample of data reported in the current literature is analyzed, and a few diffusion-controlled processes are examined. Finally a conclusion summarizes the main results of this work and presents some prospects.

\section{Theoretical background}

\subsection{Pseudo-first order rate law, K1}

The equation for pseudo-first order kinetics was introduced initially by Lagergren [8]. In the literature (e.g., in refs $[13,14,15,16,17,18]$ ), it is generally used in the form proposed by Ho and McKay [11],

$$
\ln \left[q_{e}-q(t)\right]=\ln q_{e}-k_{1} t
$$

with $q$ the amount of adsorbed solute, $q_{e}$ its value at equilibrium, $k_{1}$ the pseudo-first order rate constant and $t$ the time.

This equation may also be written in the following alternative way,

$$
q(t)=q_{e}\left[1-\exp \left(-k_{1} t\right)\right]
$$

If $q_{e}$ is determined from experiment, the fractional uptake (with respect to equilibrium)

$$
F(t) \equiv q(t) / q_{e}
$$

may be computed. Then one would have in the case of K1,

$$
F(t)=1-\exp \left(-k_{1} t\right)
$$

\subsection{Pseudo-second order rate law, K2}

The formula for pseudo-second order kinetics [9, 10] is generally employed (e.g., in refs. $[15,16,17,18])$ in the form proposed by Ho and McKay [11] as,

$$
\frac{t}{q(t)}=\frac{t}{q_{e}}+\frac{1}{k_{2} q_{e}^{2}}
$$

in which $k_{2}$ is the pseudo-second order kinetic rate constant.

Eq. 5 may be rewritten as,

$$
q(t)=q_{e} \frac{k_{2}^{*} t}{1+k_{2}^{*} t}
$$

with $k_{2}^{*} \equiv k_{2} q_{e}$, or,

$$
F(t)=\frac{k_{2}^{*} t}{1+k_{2}^{*} t}
$$




\subsection{Rate law of arbitrary order}

If we suppose that the rate law is of arbitrary order $n$, then $q$ obeys the equation,

$$
\frac{\mathrm{d} q(t)}{\mathrm{d} t}=k_{n}\left[q_{e}-q(t)\right]^{n}
$$

This rate law will be used below for a discussion in section 3.3.4.

For $n \neq 1$, the solution to this equation with $q(t=0)=0$ is,

$$
q(t)=q_{e}-\left[q_{e}^{1-n}+(n-1) k_{n} t\right]^{\frac{1}{1-n}}
$$

or

$$
F(t)=1-\left(1+k_{n}^{*} t\right)^{\frac{1}{1-n}}
$$

with $k_{n}^{*} \equiv(n-1) q_{e}^{n-1} k_{n}$.

\subsection{Assessment of data correlation quality}

In the literature about adsorption kinetics, the relations for K1 and K2, Eqs. 1 and 5, have been used extensively to describe experimental data. These two formulas are linear, of the form,

$$
\widehat{y}(t)=a t+b
$$

in which $a$ and $b$ are parameters. They have been employed to fit transformed experimental data, $y$, obtained at times $t_{i}$ for $i=1, \ldots, N$ ( $N$ being the number of data). Thus one has from Eq. 1: $y^{(1)}(t)=\ln \left[q_{e}-q(t)\right]$ and $\widehat{y}^{(1)}(t)=\ln q_{e}-k_{1} t$, in the case of $\mathrm{K} 1$; and from Eq. 5: $y^{(2)}(t)=t / q(t)$ and $\widehat{y}^{(2)}(t)=t / q_{e}+1 / k_{2} q_{e}^{2}$, in the case of $\mathrm{K} 2$.

The AARD for the function $y$ is defined by,

$$
\operatorname{AARD}_{y} \equiv \frac{1}{N} \sum_{i=1}^{N}\left|\frac{\widehat{y}_{i}-y_{i}}{y_{i}}\right|
$$

where $y_{i} \equiv y\left(t=t_{i}\right)$ and $\widehat{y}_{i} \equiv \widehat{y}\left(t=t_{i}\right)$ are the values of $y$ and $\widehat{y}$, respectively, at time $t_{i}$.

The coefficient of determination (for any model, linear or not) may be defined as $[19,20]$,

$$
R^{2} \equiv 1-\frac{\sum_{i=1}^{N}\left(y_{i}-\widehat{y}_{i}\right)^{2}}{\sum_{i=1}^{N}\left(y_{i}-\langle y\rangle\right)^{2}}
$$

in which $\langle y\rangle$ stands for the average value of the $y_{i}$ 's $(i=1, \ldots, N)$, that is $\langle y\rangle \equiv(1 / N) \sum_{i=1}^{N} y_{i}$. Note that one may get the result, $R^{2}<0$, in the case of a very bad fit using a nonlinear regression $[20,21]$.

If $a$ and $b$ in Eq. 11 are adjustable parameters, then $R^{2}$ coincides with Pearson's correlation coefficient $r^{2}$ for linear regression $\left(R^{2}=r^{2}\right)$. On the other hand, if $a$ or $b$ has a fixed value (e.g., $b=0$ ) or if the model is non-linear, this is no longer true, but $R^{2}$ may be used to assess the goodness of fit of the data by the function $\widehat{y}(t)[19,20]$.

In what follows we will suppose that $q_{e}$ is known from experiment, which is generally the case. 


\section{Results and discussion}

\subsection{Issues in data analysis}

In the majority of studies about adsorption kinetics, the experimental values for $y^{(1)}=$ $\ln \left[q_{e}-q\right]$ or $\log _{10}\left[q_{e}-q\right]$, and $y^{(2)}=t / q$, are plotted at times $t_{1}, t_{2}, \ldots, t_{N}$ by using, in the case of $y^{(1)}$, the experimental result for $q_{e}$, denoted by $q_{e, e x p}$. Next, the two sets of points are refined by performing a linear two-parameter fit of the functions $\widehat{y}^{(1)}(t)=\ln q_{e}-k_{1} t$ for $\mathrm{K} 1$ and $\widehat{y}^{(2)}(t)=t / q_{e}+1 / k_{2} q_{e}^{2}$ for K2. In these adjustments, the slopes and intercepts of the fitting line with the vertical axis $t=0$ are determined, which provides a 'calculated' value for $q_{e}$ (denoted by $q_{e, c a l}$ ), and regressed values for $k_{1}$ and $k_{2}$, and the accuracies of fit (correlation coefficient $r^{2}$ ) are computed. In each case, the value of $q_{e, c a l}$ is compared with the experimental one, $q_{e, \exp }$. The results obtained for $r^{2}$, together with those for $q_{e, c a l}$ (close or not to $q_{e, \exp }$ ?), are the criteria employed to estimate the respective accuracies and reliabilities of $\mathrm{K} 1$ and $\mathrm{K} 2$ to fit the data. In the vast majority of works published in the literature, K2 has been found to provide better correlation with experiment than K1 (which will be hereafter denoted symbolically as $\mathrm{K} 2>\mathrm{K} 1$ ).

The first issue that should be pointed out about this procedure is as follows. In most studies, a significant number of experimental data (sometimes half of the data or more) used in $\mathrm{K} 2$ plots are at, or close to, equilibrium, as may be noted, e.g., in refs. $[11,22,23,24,25,26,27]$. The fact of taking into account data at equilibrium in a kinetic study is not coherent. This pitfall constitutes the first methodological issue of these statistical treatments. It has the first consequence that, in the K2 plots of $t / q(t)$ vs. $t$, the points at equilibrium are naturally well aligned because $t / q \simeq t / q_{e}$ when $q \simeq q_{e}$. Hence, incorporation of many data at equilibrium produces a fitting straight line of slope close to $1 / q_{e, e x p}$, with a correlation coefficient $r^{2}$ close to 1 and a $q_{e, c a l}$ value close to that of $q_{e, e x p}$. This phenomenon may be observed for instance in Figure 4 of ref. [22] in which equilibrium was reached in less than $40 \mathrm{~min}$ and the data were plotted for times up to 180 min. In the extreme case, all data are at equilibrium, as in Figures 18 and 19 of ref. [11] for the data concerning $\mathrm{Cu}$. A a result, the fit is of course excellent $\left(r^{2}=1\right)$ and the fitting line for $t / q$ data passes through the origin in Figure 19 because in this case $t / q=t / q_{e}$.

On the other hand, in the case of K1, when $q$ approaches $q_{e}$, the value of $\left(q_{e}-q\right)$ becomes smaller and smaller. Hence, $\ln \left(q_{e}-q\right)$ takes very large and uncertain values (due to the uncertainty on the value of $q$ ) when $q$ gets close to its equilibrium value. This phenomenon reduces the accuracy of fit with K1.

The outcome of this methodology is that it tends to systematically favor K2 over K1. This point is illustrated in the next subsection.

There is another issue in this usual treatment, which is connected with the statistical method itself. As pointed out by statisticians, two fitting models must be compared on the original scale $[21,28]$, not on the transformed scales. In the present context, this principle means that it is irrelevant to compare $R^{2}$ values for the two different functions, $y^{(1)}=\ln \left(q_{e}-q\right)$ for $\mathrm{K} 1$, and $y^{(2)}=t / q$ for K2. Instead, the determination coefficient $R^{2}$ should be computed using Eq. 13 for the same function $y=q$ in both cases K1 and K2 so as to get a reliable estimator for the comparison of these two models [21, 28]. Moreover, in contrast with the above mentioned procedure commonly employed in the literature, leading to $q_{e, c a l}$ values, the value of $q_{e, \exp }$ will be used here once for all to compute the values of $F$ from Eq. 3, and non-linear fits using Eqs. 4 and 7 will be performed. Then the latter equations each involve only one unknown parameter: the rate constant $k_{1}$ or $k_{2}^{*}$. 


\subsection{Illustration}

In this part we first construct a function $q(t)$ mimicking experimental data by computing the function,

$$
q(t) \equiv[1+\varepsilon(t)] q_{0}(t)
$$

in which $q_{0}$ obeys first order kinetics

$$
q_{0}(t) \equiv 1-e^{-t}
$$

which has a rate constant $k=1$ and equilibrium capacity $q_{0, e}=1$ (in arbitrary units), and $\varepsilon(t)$ represents the uncertainty on the measurement of $q_{0}$. The function $\varepsilon(t)$ was taken to be a random function with values in the range -0.015 to 0.015 , which corresponds to a maximum uncertainty of $\pm 1.5 \%$. The values of $q_{0}$ and $\varepsilon$ were generated for 20 time values uniformly distributed in the range 0 to 8 by using a FORTRAN program.

A plot of $q(t)$ is shown in Figure 1 . It is seen that $q$ is equilibrated for $t \gtrsim 4$. The equilibrium value of $q$ computed from the data between $t=4.4$ and $t=8$ is $q_{e, \exp }=1.0005$, which is very close to the equilibrium value of $q_{0}\left(q_{0, e}=1\right)$ in Eq. 15 .

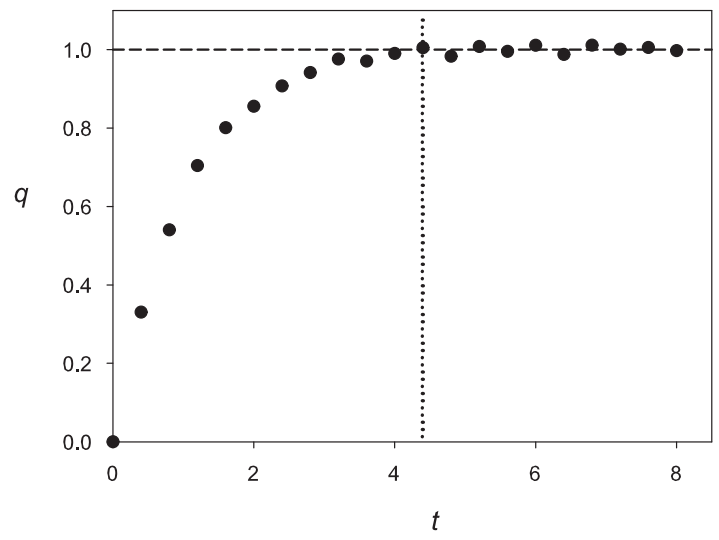

Figure 1: Simulated experimental results for $\mathrm{q}(\mathrm{t})$ (first order kinetics). Horizontal dashed line: equilibrium value of $q$. Vertical dotted line indicates the first point for which $q$ is (slightly) above $q_{e}$ at $t=4.4$.

Now one may ask the following question: does one find that these data are indeed better described by $\mathrm{K} 1$ if one follows the usual procedure depicted in section 3.1 ?

If one proceeds in this way one obtains the results presented in the first two lines of Table 1. They are plotted in Figure 2 for K1 and in Figure 3 for K2. In the case of K1, the adjustment was limited to $t=4$ because the next experimental point (for $t=4.4$ ) is greater than $q_{e}$ and the value of $\ln \left[q_{e}-q(t)\right]$ cannot be computed for this point. On the other hand, in the case of $\mathrm{K} 2$, all data points up to $t=8$ could be used in the fit.

Table 1: Results of two-parameter fits using Eqs. 1 and 5.

\begin{tabular}{cccccc}
\hline Rate law & Equation & $t_{\max }{ }^{a}$ & $k^{b}$ & $q_{e, \text { cal }}$ & $r^{2}$ \\
\hline K1 & 1 & 4 & 1.101 & 1.114 & 0.9817 \\
K2 & 5 & 8 & 1.820 & 1.100 & 0.9961 \\
\hline${ }^{a}$ Maximum time of fit; ${ }^{b}$ Rate constant $\left(k_{1}\right.$ or $\left.k_{2}\right)$.
\end{tabular}

One notices in Table 1 that optimum adjustment is obtained with K2 because it gives the best coefficient of correlation (higher $r^{2}$ value) and a value for $q_{e, c a l}$ that is in slightly 


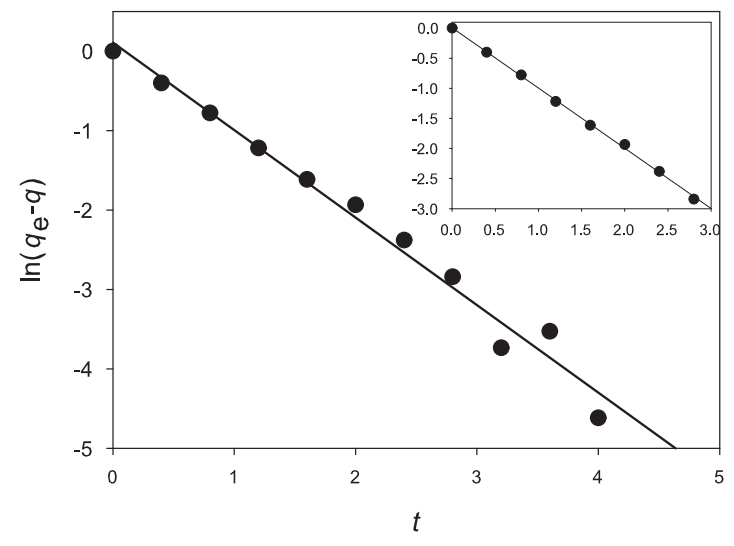

Figure 2: Two-parameter fit of $\ln \left[q_{e}-q(t)\right]$ with $\mathrm{K} 1$ using Eq. 1 for $t \leq 4$. Insert: Fit for $t<3 .(\bullet)=$ data; solid lines $=$ results of fit.

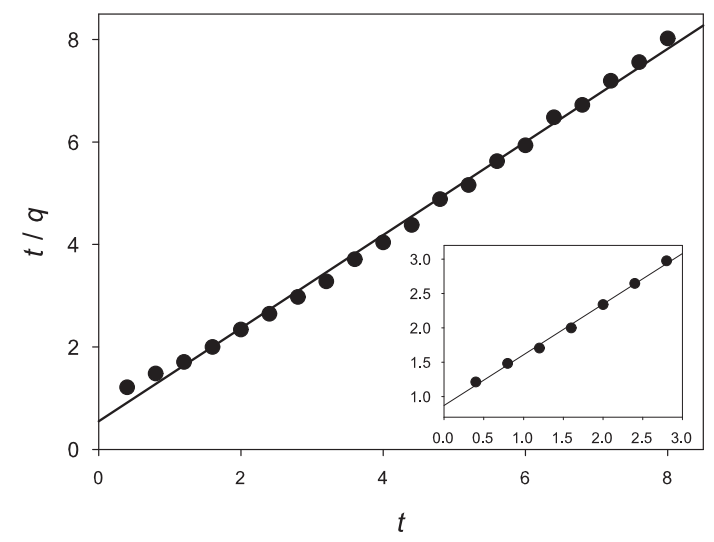

Figure 3: Two-parameter fit of $t / q(t)$ with K2 using Eq. 5 for $t \leq 8$. Insert: Fit for $t<3$. $(\bullet)=$ data; solid lines $=$ results of fit.

better agreement with $q_{e, \exp } \sim 1$. With K1, the deviation of $\ln \left[q_{e}-q(t)\right]$ from linear behavior when $q$ approaches $q_{e}$ is observed on the last 3 points in Figure 2 (for $t>3$ ), which makes $q_{e, c a l}$ deviate from unity and reduces the value of $r^{2}$. Better fit is obtained with $\mathrm{K} 2$ at the cost of a $k$ value that deviates much from its actual value (1.82 vs. 1, respectively). However, it is clear that this flaw would get unnoticed by an experimentalist analyzing the data with $\mathrm{K} 2$.

An experimentalist using this procedure would therefore conclude (erroneously) that the data are better correlated with K2. This example illustrates the first issue in the common analysis of kinetic results.

However, as mentioned at the end of section 3.1 (the second issue in the comparison of $\mathrm{K} 1$ and K2), the two models K1 and K2 should be compared for their ability to describe the same quantity, $q$ or the fractional uptake $F$.

Similar non-linear fits have been used in a few rare cases in the literature [26, 29]. In this work a FORTRAN program based on a classic Marquardt least-squares algorithm was used to regress the values of $k_{1}$ and $k_{2}^{*}$ in Eqs. 4 and 7 (with $q_{e}=1$ ). The fits were done on the time interval, $0<t<3$ in order to eliminate data too close to equilibrium. Otherwise, this type of non-linear fit may be performed with many free or commercial softwares (Gnuplot plotting program was also used in this work). Model comparison was 
done by computing the values of the coefficient of determination $R^{2}$ [28] and the AARD for $q$ for the two rate laws. Let us note that least-squares fit maximizes the value of $R^{2}$ because it minimizes the sum $\sum_{i=1}^{N}\left(y_{i}-\widehat{y}_{i}\right)^{2}$ (see Eq. 13). This is not the case of AARD, which provides additional information about the quality of fit.

The results for these non-linear fits are summarized in Table 2 and in Figure 4. It is noticed that $R^{2}$ is close to 1 for $\mathrm{K} 1$ and significantly lower for K2. Note that it would have been possible to include data at equilibrium in these non-linear fits, but this would have increased the value of the coefficient of determination for both K1 and K2 and it would have reduced the 'contrast' between them, which is not desirable. This metrics therefore correctly identifies the rate law and it clearly discriminates between the two formulas. Figure 4 shows that K1 indeed describes the data much better than K2, as expected from Eq. 15. This result is confirmed by the AARD values for $q$ given in Table 2 .

Table 2: Results of one-parameter fits using Eqs. 4 and 7 for $t<3$.

\begin{tabular}{ccccc}
\hline Rate law & Equation & $k$ & $R^{2}$ & AARD $_{F}$ \\
\hline K1 & 2 & 0.9949 & 0.9992 & $0.7 \%$ \\
K2 & 6 & 1.952 & 0.8700 & $11.1 \%$ \\
\hline
\end{tabular}

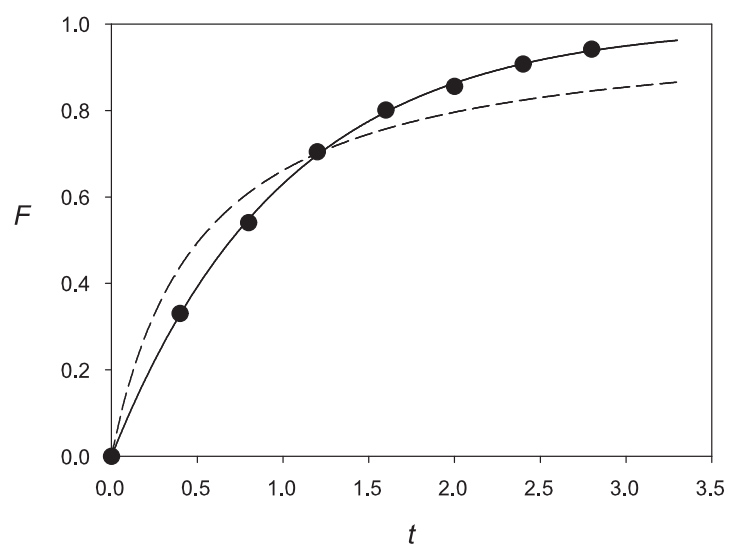

Figure 4: Non-linear fits of $F(t)$ data for $t<3$ (with $\left.q_{e}=1\right) .(\bullet)=$ data for $F$; solid line = result of fit with K1 (Eq. 4); dashed line = result of fit with K2 (Eq. 7).

\subsection{Analysis of literature experimental data.}

\subsubsection{Criteria for determination of best rate equation}

The capability of K1 and K2 equations to describe experimental kinetic data has been assessed by fitting these rate laws to experimental data. Unless otherwise indicated, the values for the latter were obtained by digitalizing figures in the articles with the use of Engauge Digitizer 4.1 (free) software.

Data at and near equilibrium were not included in the treatment. Hence, in the fits, it was chosen to consider data corresponding to a maximum fractional uptake of $85 \%$ $(F \leq 0.85)$. This value was thought to be a good compromise between taking data too close to equilibrium and taking too low a value which would have led to reject too many data points. After application of this condition, only data sets containing at least 3 experimental points were retained for analysis. 
Then, the respective merits of rate laws $\mathrm{K} 1$ and $\mathrm{K} 2$ were examined by using statistical analysis and by following recommendations from NIST [30]. In consequence, the coefficients of determination $\left(R^{2}\right)$ (Eq. 13) and the residues $\left(\equiv F_{i, \text { exp }}-F_{i, c a l}\right.$, for $\left.i=1 \ldots N\right)$ were examined for fits with K1 and K2. Moreover, additional information was provided by computing the average absolute relative deviation (AARD) of fit.

Hereafter, a rate equation (K1 or K2) will be declared to fit the data well if it provides the higher $R^{2}$ value. Following the recommendation from a statistician [19], the $R^{2}$ value will also have to satisfy the condition: $R^{2}>0.8$. Furthermore, because sometimes the latter condition is not sufficient $[19,30]$, the residues will have to be distributed sufficiently randomly around zero when considered as a function of the number $i(=1, \ldots, N)$ of the data point [30]. If for instance, in a plot of $F$ vs. time, the first experimental points are located above the fitting curve and if the last points are located below, then the corresponding equation should be rejected.

\subsubsection{Data considered in ref. [11].}

In this part, the experimental data $[13,14,31,32,33,34,35,36,37,38,39,40]$ analyzed by Ho and McKay in 1999 [11] are examined in the light of the preceding section.

Data values were generally found by digitalizing the figures published in the articles, or numerical values were found directly in refs. [39, 40]. Besides, the experimental data used in ref. [31] could not be found in this reference. Those reported in refs. [32] and [33] could not be analyzed because all of them were too close to equilibrium (see also Figure 18 of ref. [11]). The data of ref. [34] did not attain equilibrium. Only those at $323 \mathrm{~K}$ could be obtained in ref. [35] because the equilibrium value of $q$ was not reported at other temperatures.

The results of the fits using Eqs. 4 and 7 are summarized in Table 3, by following the order the figures of ref. [11] were presented. The coefficients of determination $R_{1}^{2}$ and $R_{2}^{2}$, and the average relative deviations $\mathrm{AARD}_{F} 1$ and $\mathrm{AARD}_{F} 2$, were computed for $\mathrm{K} 1$ and K2, respectively. As mentioned in the previous subsection 3.3.1, the best equation had to satisfy the conditions: higher $R^{2}$ value, $R^{2}>0.8$, and good pattern for the residues.

Examples of plots illustrating the results of Table 3 are presented in Figures 5, 6 and 7, in cases where $\mathrm{K} 1>\mathrm{K} 2, \mathrm{~K} 2>\mathrm{K} 1$, and both $\mathrm{K} 1$ and $\mathrm{K} 2$ being unsatisfactory, respectively.

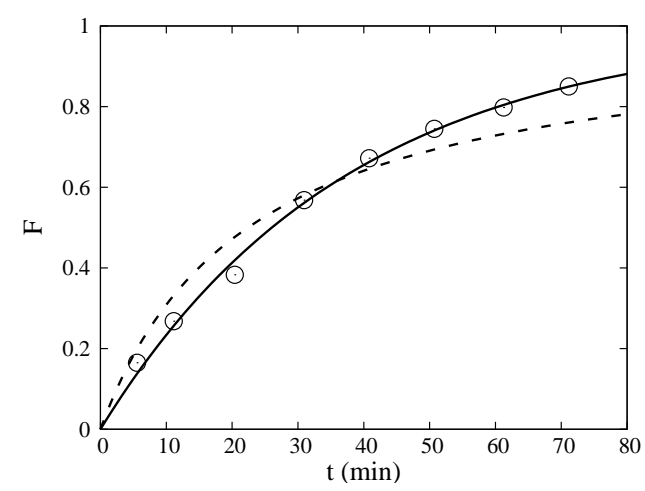

Figure 5: Example of case K1 > K2: data from ref. [37] at $15 \mathrm{mg} / \mathrm{L}$ of PHC. $(\odot)=$ experimental data; solid line $=$ fit with $\mathrm{K} 1$; dashed line $=$ fit with $\mathrm{K} 2$.

These results call for some comments as follows. 
Table 3: Results of non-linear one-parameter fits, using Eqs. 4 and 7, of data analyzed in Ref. [11]. In the latter reference, all systems were marked as obeying to K2.

\begin{tabular}{|c|c|c|c|c|c|c|c|c|}
\hline Reference & Conditions & $N^{a}$ & $R_{1}^{2}$ & $R_{2}^{2}$ & $\mathrm{AARD}_{F} 1$ & $\mathrm{AARD}_{F} 2$ & $\mathrm{~K} 1^{b}$ & $\mathrm{~K} 2^{c}$ \\
\hline [13] & $10^{-4} \mathrm{M}$ & 3 & $\frac{1}{-1.72}$ & 0.735 & $9.9 \%$ & $2.9 \%$ & $0^{d}$ & 0 \\
\hline \multirow[t]{4}{*}[36]{} & $50 \mathrm{mg} / \mathrm{L}$ & 5 & -1.98 & 0.643 & $12.8 \%$ & $4.6 \%$ & 0 & 0 \\
\hline & $75 \mathrm{mg} / \mathrm{L}$ & 6 & 0.361 & 0.922 & $10.8 \%$ & $4.1 \%$ & & $\checkmark$ \\
\hline & $100 \mathrm{mg} / \mathrm{L}$ & 4 & 0.789 & 0.920 & $11.0 \%$ & $6.8 \%$ & & $\checkmark$ \\
\hline & $125 \mathrm{mg} / \mathrm{L}$ & 6 & 0.888 & 0.963 & $7.5 \%$ & $3.5 \%$ & & $\checkmark$ \\
\hline [35] & $323 \mathrm{~K}$ & 5 & 0.640 & 0.995 & $10.6 \%$ & $1.1 \%$ & & $\checkmark$ \\
\hline \multirow[t]{6}{*}[37]{} & $10 \mathrm{mg} / \mathrm{L}-\mathrm{PHC}$ & 8 & 0.996 & 0.944 & $4.8 \%$ & $18.9 \%$ & $\checkmark$ & \\
\hline & $15 \mathrm{mg} / \mathrm{L}-\mathrm{PHC}$ & 8 & 0.995 & 0.935 & $4.3 \%$ & $12.6 \%$ & $\checkmark$ & \\
\hline & $20 \mathrm{mg} / \mathrm{L}-\mathrm{PHC}$ & 8 & 0.980 & 0.964 & $8.3 \%$ & $6.2 \%$ & $\checkmark$ & \\
\hline & $10 \mathrm{mg} / \mathrm{L}-\mathrm{GAC}$ & 5 & 0.906 & 0.976 & $15.8 \%$ & $7.1 \%$ & & $\checkmark$ \\
\hline & $15 \mathrm{mg} / \mathrm{L}-\mathrm{GAC}$ & 5 & 0.943 & 0.976 & $13.7 \%$ & $9.3 \%$ & & $\checkmark$ \\
\hline & $20 \mathrm{mg} / \mathrm{L}-\mathrm{GAC}$ & 5 & 0.952 & 0.975 & $13.3 \%$ & $9.1 \%$ & & $\checkmark$ \\
\hline \multirow[t]{4}{*}{ [38] } & $2 \mathrm{ppm}$ & 3 & 0.991 & 0.899 & $3.3 \%$ & $17.3 \%$ & $\checkmark$ & \\
\hline & $5 \mathrm{ppm}$ & 3 & 0.998 & 0.932 & $4.1 \%$ & $19.7 \%$ & $\checkmark$ & \\
\hline & $20 \mathrm{ppm}$ & 3 & 0.999 & 0.931 & $1.2 \%$ & $7.5 \%$ & $\checkmark$ & \\
\hline & $30 \mathrm{ppm}$ & 5 & 0.978 & 0.962 & $6.2 \%$ & $8.5 \%$ & $0^{d}$ & 0 \\
\hline \multirow[t]{5}{*}{ [14] } & $5 \mathrm{mg} / \mathrm{L}-30^{\circ} \mathrm{C}$ & 4 & 0.404 & 0.956 & $15.1 \%$ & $4.0 \%$ & & $\checkmark$ \\
\hline & $10 \mathrm{mg} / \mathrm{L}-30^{\circ} \mathrm{C}$ & 4 & 0.306 & 0.928 & $15.8 \%$ & $4.8 \%$ & & $\checkmark$ \\
\hline & $20 \mathrm{mg} / \mathrm{L}-30^{\circ} \mathrm{C}$ & 5 & 0.953 & 0.975 & $13.3 \%$ & $9.1 \%$ & $0^{d}$ & 0 \\
\hline & $10 \mathrm{mg} / \mathrm{L}-40^{\circ} \mathrm{C}$ & 4 & 0.594 & 0.969 & $14.6 \%$ & $3.7 \%$ & & $\checkmark$ \\
\hline & $10 \mathrm{mg} / \mathrm{L}-50^{\circ} \mathrm{C}$ & 4 & 0.552 & 0.976 & $15.2 \%$ & $3.4 \%$ & & $\checkmark$ \\
\hline \multirow[t]{2}{*}{ [39] } & Rinsed & 12 & -0.249 & 0.596 & $29.6 \%$ & $17.1 \%$ & $0^{d}$ & 0 \\
\hline & Unrinsed & 9 & -5.28 & -1.88 & $22.8 \%$ & $16.4 \%$ & 0 & 0 \\
\hline \multirow[t]{4}{*}[40]{} & $1 \mathrm{mg} / \mathrm{L}$ & 3 & 0.767 & 0.892 & $26.5 \%$ & $23.8 \%$ & 0 & 0 \\
\hline & $2 \mathrm{mg} / \mathrm{L}$ & 4 & -0.430 & 0.751 & $18.7 \%$ & $7.8 \%$ & 0 & 0 \\
\hline & $4 \mathrm{mg} / \mathrm{L}$ & 5 & -0.726 & 0.609 & $20.2 \%$ & $8.5 \%$ & 0 & 0 \\
\hline & $6 \mathrm{mg} / \mathrm{L}$ & 6 & -4.61 & -2.24 & $47.7 \%$ & $35.3 \%$ & 0 & 0 \\
\hline
\end{tabular}

${ }^{a}$ Number of data; ${ }^{b} \mathrm{~K} 1>\mathrm{K} 2 ;{ }^{c} \mathrm{~K} 2>\mathrm{K} 1 ;{ }^{d} \mathrm{~K} 1$ and $\mathrm{K} 2$ both giving bad fits.

The data of ref. [37] are better represented by $\mathrm{K} 1$ in the case of PHC activated carbon (see also Figure 5), and by K2 in the case of GAC.

The data of ref. [38] at $30 \mathrm{ppm}$ and those of ref. [14] at $20 \mathrm{mg} / \mathrm{L}$ give high values for $R_{1}^{2}$ and $R_{2}^{2}$, respectively. Those of ref. [40] at $1 \mathrm{mg} / \mathrm{L}$ yield a satisfactory value for $R_{2}^{2}$. However, in these 3 cases, it was observed that the residues exhibited non-random variation with time. Consequently the respective kinetics (K1 in the first case and K2 and in the last two cases) were rejected and it was concluded that neither rate equation described the data well. These were the only cases of rejection in this second step of statistical analysis for data of Table 3. An example is shown in Figure 7 for the data of ref. [38] at $30 \mathrm{ppm}$, for which $R^{2}$ has the higher value out of the 3 cases $\left(R_{1}^{2}=0.978\right)$. It is seen in this plot that the residues for $\mathrm{K} 1$ are positive for the first 2 points and negative for the last 3 points, which is not satisfactory.

All data of ref. [40] were better described with $\mathrm{K} 2$ than with K1, but the fits were not very good, because K2 and even more so K1 cannot capture the short time, and the long time, behaviors (fast initial rise followed by a leveling off) at the same time.

It is seen in Table 3 that K1 gives significantly better fits than K2 in 6 cases (K1 > 


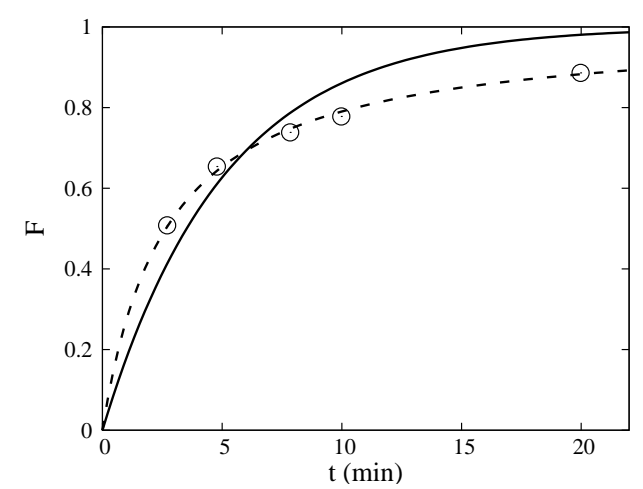

Figure 6: Example of case K2 > K1: data from ref. [35] at $323 \mathrm{~K} .(\odot)=$ experimental data; solid line $=$ fit with $\mathrm{K} 1$; dashed line = fit with $\mathrm{K} 2$.

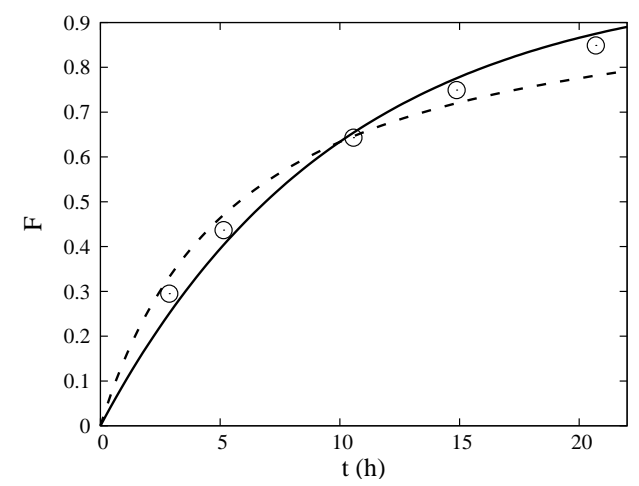

Figure 7: Example of case where K1 and K2 do not fit the data well: data from ref. [38] at $30 \mathrm{ppm}$. $(\odot)=$ experimental data; solid line $=$ fit with $\mathrm{K} 1$; dashed line $=$ fit with $\mathrm{K} 2$. Here $\mathrm{K} 1$ is rejected although $R_{1}^{2}=0.978$ because of unsatisfactory behavior of residues (see text).

$\mathrm{K} 2$ ), and the reverse situation (K2 > K1) occurs in 11 cases. Neither is satisfactory in 10 cases.

The overall trend in the results of this section is that $\mathrm{K} 2$ gives a better fit more frequently than K1, for the systems that were examined in ref. [11]. However the situation is much less contrasted than suggested in this latter reference and subsequent literature dealing with adsorption kinetics, in which $\mathrm{K} 2$ was nearly always the best rate equation. Now K1 performs better than K2 in a significant number of cases. Moreover, the coefficient of determination for $\mathrm{K} 2\left(R_{2}^{2}\right)$ is not as high as found before in the literature where it was generally very close to 1 . Lastly, in 9 out of the 10 cases where neither rate equation fits the data well, it is observed that K2 gives better results than K1.

\subsubsection{Data reported in 2015}

The current literature was also examined by picking randomly 10 papers in the nearly thousand published (sometimes online) in 2015, that quoted the paper by Ho and McKay [11].

All of these works [41, 42, 43, 44, 45, 46, 47, 48, 49, 50] concluded that K2 better described the experimental kinetic data, except in ref. [49] in which $\mathrm{K} 1$ gave a better fit 
in the case of $\mathrm{As}(\mathrm{V})$ adsorption (while $\mathrm{K} 2$ was more satisfactory in the case of $\mathrm{Cr}(\mathrm{III})$ and $\mathrm{Cr}(\mathrm{VI}))$.

Among these publications 4 could not be used because all of the data were at equilibrium $[41,42,43,44]$. As a consequence, these studies unsurprisingly reported better performance of $\mathrm{K} 2$ over $\mathrm{K} 1$ as noted in section 3.1. In other works [45, 46] experimental data were not reported.

The data of the remaining 4 papers were reexamined in the light of the present work. The results are collected in Table 4. Examples of fits in which $\mathrm{K} 1>\mathrm{K} 2, \mathrm{~K} 2>\mathrm{K} 1$ and neither formula is successful are presented in Figures 8,9 and 10, respectively.

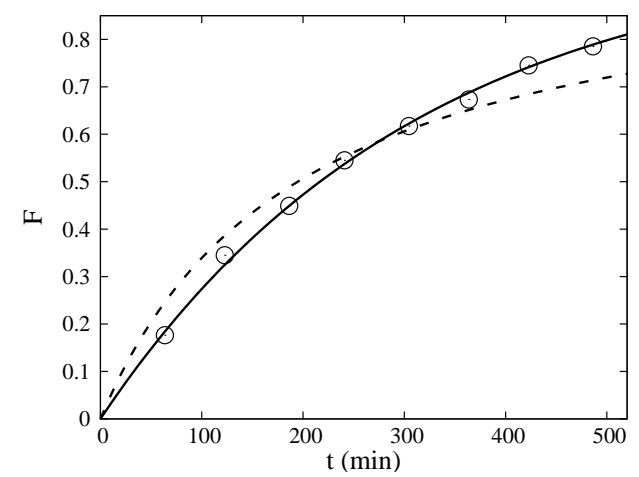

Figure 8: Example of case $\mathrm{K} 1>\mathrm{K} 2$ : data from ref. [47] at $200 \mathrm{mg} / \mathrm{L} .(\odot)=$ experimental data; solid line $=$ fit with $\mathrm{K} 1$; dashed line $=$ fit with $\mathrm{K} 2$.

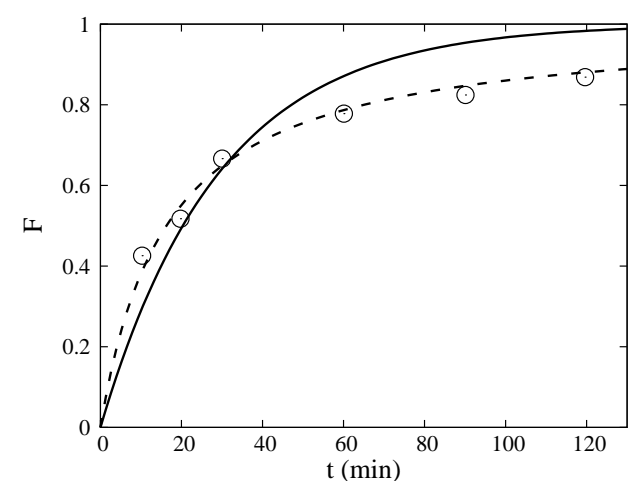

Figure 9: Example of case $\mathrm{K} 2>\mathrm{K} 1$ : data from ref. [48] at $40^{\circ} \mathrm{C} .(\odot)=$ experimental data; solid line $=$ fit with K1; dashed line = fit with K2.

A few remarks should be made about these results.

The data of ref. [47] at $300 \mathrm{mg} / \mathrm{L}$ are fitted with $\mathrm{K} 1$ with a high $R_{1}^{2}$ value of $0.992 \mathrm{but}$ AARD $_{F} 1$ is a bit large $(\sim 11.1 \%)$. This is due to a discrepancy at short times where the fitting line is above the data points (not shown). The other points are well described by K1.

In the case of ref. [48] at $50^{\circ} \mathrm{C}$ and that of ref. [50] at $44.7 \mathrm{mg} / \mathrm{L}$, the criterion $R^{2}>0.8$ is satisfied, but the residues have a rather unsatisfactory behavior (not shown), which led to reject K2 for both systems. These were the only such cases of rejection in this table. 


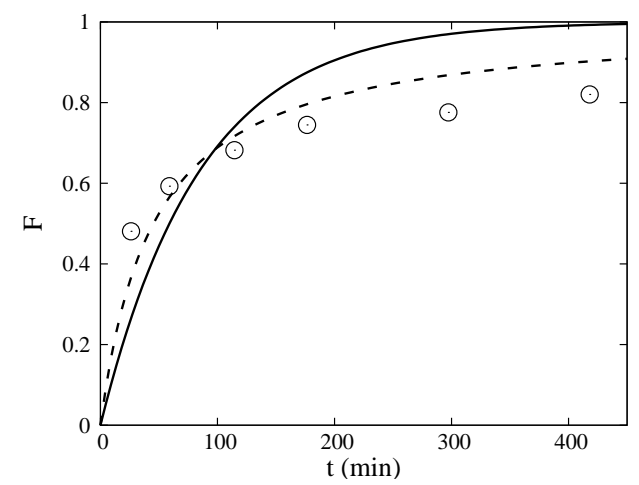

Figure 10: Example of case where K1 and K2 both unsuccessful: data from ref. [50] at $178.8 \mathrm{mg} / \mathrm{L}$. $(\odot)=$ experimental data; solid line $=$ fit with $\mathrm{K} 1$; dashed line $=$ fit with $\mathrm{K} 2$.

When looking at the results for $\mathrm{Cr}(\mathrm{VI}) / \mathrm{p}(\mathrm{APTMAC} 1)$ from ref. [49], one notices that $R_{1}^{2}>R_{2}^{2}$ and $\mathrm{AARD}_{F} 1>\mathrm{AARD}_{F} 2$, which are contradictory indicators. As shown in Figure 11 this peculiarity originates from the fact that the first two data points are well described by K2, but not well fitted with K1, which produces a larger AARD with this latter rate equation.

The data of ref. [50] at the four higher concentrations exhibit the same following pattern in the fit with K2 (which performs better in every case). The first two experimental points are placed above the fitting curve and the remaining points at larger time are placed below the curve (not shown). These data exhibit a fast initial rise that cannot be represented correctly by either rate law. The residues are positive for the first two points at lower times and negative after that. This is why this rate law was rejected in the case of $44.7 \mathrm{mg} / \mathrm{L}$ though the $R_{2}^{2}$ value was larger than 0.8 .

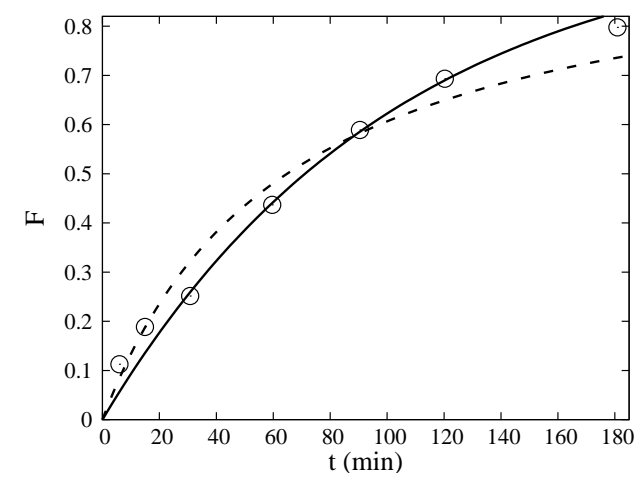

Figure 11: Data from ref. [49] for $\mathrm{Cr}(\mathrm{VI}) / \mathrm{p}(\mathrm{APTMAC} 1) .(\odot)=$ experimental data; solid line $=$ fit with $\mathrm{K} 1$; dashed line $=$ fit with K2. For these data, $R_{1}^{2}>R_{2}^{2}$ and $\mathrm{AARD}_{F} 1>\mathrm{AARD}_{F} 2$ (see text)

The main features in the results of this section are that $\mathrm{K} 1$ and $\mathrm{K} 2$ give better fits in 10 and 8 cases, respectively, which situation is opposite to that of Table 3. Neither is satisfactory in 5 cases although, as in the preceding section, K2 gives markedly better results than $\mathrm{K} 1$ in these cases. 
Table 4: Results of non-linear one-parameter fits, using Eqs. 4 and 7, for data reported in 2015. All of these references concluded that K2 was the best rate law, except in ref. [49] in the case of As(V) (see text).

\begin{tabular}{clccccccc}
\hline Reference & Conditions & $N^{a}$ & $R_{1}^{2}$ & $R_{2}^{2}$ & AARD $_{F} 1$ & AARD $^{2}$ & $\mathrm{~K}^{b}$ & $\mathrm{~K}^{c}$ \\
\hline$[47]$ & $50 \mathrm{mg} / \mathrm{L}$ & 7 & 0.969 & 0.916 & $4.8 \%$ & $9.8 \%$ & $\checkmark$ & \\
& $100 \mathrm{mg} / \mathrm{L}$ & 8 & 0.986 & 0.924 & $7.6 \%$ & $18.3 \%$ & $\checkmark$ & \\
& $200 \mathrm{mg} / \mathrm{L}$ & 8 & 0.997 & 0.942 & $2.0 \%$ & $10.4 \%$ & $\checkmark$ & \\
& $300 \mathrm{mg} / \mathrm{L}$ & 9 & 0.992 & 0.933 & $11.1 \%$ & $27 \%$ & $\checkmark$ & \\
& $400 \mathrm{mg} / \mathrm{L}$ & 8 & 0.986 & 0.964 & $3.6 \%$ & $7.7 \%$ & $\checkmark$ & \\
& $500 \mathrm{mg} / \mathrm{L}$ & 9 & 0.995 & 0.970 & $4.4 \%$ & $9.7 \%$ & $\checkmark$ & \\
{$[48]$} & $20^{\circ} \mathrm{C}$ & 4 & 0.703 & 0.964 & $9.8 \%$ & $3.6 \%$ & & $\checkmark$ \\
& $30^{\circ} \mathrm{C}$ & 5 & 0.604 & 0.964 & $11.4 \%$ & $4.1 \%$ & & $\checkmark$ \\
& $40^{\circ} \mathrm{C}$ & 6 & 0.639 & 0.978 & $13.4 \%$ & $3.8 \%$ & & $\checkmark$ \\
& $50^{\circ} \mathrm{C}$ & 8 & 0.478 & 0.942 & $16.9 \%$ & $5.4 \%$ & $0^{d}$ & 0 \\
& $\mathrm{As}(\mathrm{V}) / \mathrm{amid}-\mathrm{p}$ & 9 & 0.985 & 0.991 & $13.6 \%$ & $12.5 \%$ & & $\checkmark$ \\
& $\mathrm{As}(\mathrm{V}) / \mathrm{p}(\mathrm{APTMAC} 1)$ & 7 & 0.957 & 0.921 & $13.7 \%$ & $16.3 \%$ & $\checkmark$ & \\
& $\mathrm{Cr}(\mathrm{VI}) / \mathrm{amid}-\mathrm{p}$ & 10 & 0.989 & 0.984 & $7.4 \%$ & $13.5 \%$ & $\checkmark$ & \\
& $\mathrm{Cr}(\mathrm{VI}) / \mathrm{p}(\mathrm{APTMAC} 1)$ & 7 & 0.983 & 0.968 & $12.4 \%$ & $11.3 \%$ & $\checkmark$ & \\
& $\mathrm{Cr}(\mathrm{III}) / \mathrm{amid}-\mathrm{p}$ & 7 & 0.985 & 0.953 & $12.8 \%$ & $16.5 \%$ & $\checkmark$ & \\
& $\mathrm{Cr}(\mathrm{III}) / \mathrm{p}(\mathrm{APTMAC} 1)$ & 6 & 0.880 & 0.966 & $21.4 \%$ & $7.6 \%$ & & $\checkmark$ \\
& $22.3 \mathrm{mg} / \mathrm{L}$ & 3 & 0.690 & 0.990 & $7.3 \%$ & $1.3 \%$ & & $\checkmark$ \\
& $44.7 \mathrm{mg} / \mathrm{L}$ & 6 & -0.129 & 0.836 & $17.3 \%$ & $6.8 \%$ & $0^{d}$ & 0 \\
& $89.4 \mathrm{mg} / \mathrm{L}$ & 7 & -0.436 & 0.672 & $21.7 \%$ & $10.3 \%$ & 0 & 0 \\
& $178.8 \mathrm{mg} / \mathrm{L}$ & 6 & -0.781 & 0.589 & $21.1 \%$ & $10.4 \%$ & 0 & 0 \\
& $223.5 \mathrm{mg} / \mathrm{L}$ & 6 & -0.514 & 0.690 & $21.7 \%$ & $9.8 \%$ & 0 & 0 \\
\hline
\end{tabular}

${ }^{a}$ Number of data; ${ }^{b} \mathrm{~K} 1>\mathrm{K} 2 ;{ }^{c} \mathrm{~K} 2>\mathrm{K} 1 ;{ }^{d} \mathrm{~K} 1$ and $\mathrm{K} 2$ both bad.

\subsubsection{Systems controlled by diffusion}

Finally one may ask the following question: which of the two rate laws better describes an adsorption process controlled by diffusion?

A first difficulty to answer this question is that few systems have been marked as being limited by diffusion without ambiguity. In this work this question was addressed by using experimental data from Yang and Al-Duri [51] and Choy et al. [52] in which the adsorbent was constituted of commercial active carbon (Filtrasorb 400). In a previous study [5], these two systems were identified as being controlled by diffusion. We arrived at this conclusion because the fractional uptake at short times was observed to vary not only as $\sqrt{t}$ (for $F \leq 0.4$ ), but also to be inversely proportional to the square root of the initial solute concentration in the batch adsorber. This non-trivial property may be an additional key characteristic of such processes. It is in contrast with descriptions based on the formula derived by Crank for pure diffusion into a sphere (in the absence of adsorption) (Eq. (6.20) of ref. [53]) in which the fractional uptake is independent of solute concentration. These descriptions include the work of Boyd et al. [1] who used this formula for the first time, and the well-known "intra-particle diffusion" (IPD) equation $[2,3]$. We have shown that the IPD diffusion coefficient is a lumped parameter which depends on the experimental conditions [5].

Non-linear two-parameter fits using Eq. 10 (hereafter denoted by Kn) were performed on the data of refs. [51] and [52] (such that $F \leq 0.85$ ) in order to determine, for every concentration, the rate order $n\left(\right.$ and $k_{n}^{*}$ ) that gave the best adjustment. 
The results are collected in Table 5, together with those for fits with K1 and K2. They show that adjustments can be obtained with this procedure for orders $n$ that are in the range of 1.9 to 2.5 for the data of ref. [51] and of 4 to 12 for those of ref. [52].

Table 5: Diffusion controlled processes : Results of fits using Eq. 10 for the data of refs. [51] and [52].

\begin{tabular}{ccccccccccr}
\hline Reference & Conditions & $F_{\max }$ & $N^{a}$ & $R_{1}^{2}$ & $R_{2}^{2}$ & $\mathrm{AARD}_{F} 1$ & $\mathrm{AARD}_{F} 2$ & $n$ & $R_{n}^{2}$ & $\mathrm{AARD}_{F} n$ \\
\hline$[51]$ & $35.4 \mathrm{mg} / \mathrm{L}$ & 0.826 & 10 & 0.931 & 0.984 & $20.0 \%$ & $9.9 \%$ & 1.93 & 0.985 & $10.1 \%$ \\
& $60.3 \mathrm{mg} / \mathrm{L}$ & 0.830 & 12 & 0.934 & 0.987 & $22.6 \%$ & $11.6 \%$ & 2.03 & 0.987 & $11.5 \%$ \\
& $87.2 \mathrm{mg} / \mathrm{L}$ & 0.841 & 15 & 0.889 & 0.976 & $29.5 \%$ & $17.3 \%$ & 2.45 & 0.982 & $13.6 \%$ \\
{$[52]$} & $131 \mathrm{mg} / \mathrm{L}$ & 0.840 & 16 & 0.903 & 0.985 & $29.3 \%$ & $15.6 \%$ & 2.34 & 0.988 & $13.0 \%$ \\
& $50 \mathrm{ppm}$ & 0.530 & 8 & 0.740 & 0.897 & $31.8 \%$ & $20.5 \%$ & 4.04 & 0.988 & $6.5 \%$ \\
& $75 \mathrm{ppm}$ & 0.456 & 10 & 0.773 & 0.872 & $42.7 \%$ & $34.2 \%$ & 5.30 & 0.973 & $15.3 \%$ \\
& $100 \mathrm{ppm}$ & 0.383 & 9 & 0.763 & 0.856 & $39.5 \%$ & $32 \%$ & 5.98 & 0.979 & $12.0 \%$ \\
& $150 \mathrm{ppm}$ & 0.313 & 8 & 0.628 & 0.742 & $37.7 \%$ & $31.9 \%$ & 7.99 & 0.980 & $7.9 \%$ \\
& $200 \mathrm{ppm}$ & 0.252 & 10 & 0.630 & 0.701 & $49.3 \%$ & $45.4 \%$ & 12.3 & 0.961 & $16.2 \%$ \\
\hline
\end{tabular}

It is observed that the value of $n$ increases notably from the top to the bottom of this table. It was found that this is due to the maximum value of $F$, denoted by $F_{\max }$, to which the fit is done. For the data of ref. [51], $F_{\max }$ is a little greater than 0.8 and $n$ is of the order of 2 . In contrast, the data of ref. [52] correspond to values of $F_{\max }$ that vary from 0.53 to 0.25 when the initial solute concentration is increased from $50 \mathrm{ppm}$ to 200 ppm. The hypothesis of increase of $n$ when $F_{\max }$ decreases was confirmed by considering the data of ref. [51] at $60.3 \mathrm{mg} / \mathrm{L} \mathrm{ppm}$ for which 12 points are available and $n \simeq 2$. For this data set, successive fits were performed in which the last point was removed after each fit, so that the number of data points was successively $12,11,10, \ldots$. The results from this procedure are shown in Table 6 . It is found that $n$ increases from $\sim 2$ to $\sim 4.3$ when the number of points is reduced from 12 to 5 and $F_{\max }$ decreases from 0.83 to 0.38 . One may notice that different values of $n$ are obtained for the same value of $F_{\text {max }}$ in Tables 5 and 6, e.g., for $F_{\max } \sim 0.38, n \sim 6$ for $100 \mathrm{ppm}$ (ref. [52] in Table 5), and $n \sim 4.3$ for $N=5$ (ref. [51] in Table 6). This may seem surprising because, for these 2 systems, $F$ varies identically as $t^{1 / 2}$ for $F \lesssim 0.4$ [5], which should lead to the same value of $n$ for a given value of $F_{\max }$. The difference in the results for this parameter originates from the fact that the fits were done with different numbers and values of data points.

Table 6: Results of successive fits using Eq. 10 for the data of ref. [51] at $60.3 \mathrm{mg} / \mathrm{L}$.

\begin{tabular}{rrr}
\hline$N^{a}$ & $F_{\max }$ & $n$ \\
\hline 12 & 0.830 & 2.03 \\
11 & 0.787 & 2.20 \\
10 & 0.694 & 2.53 \\
9 & 0.626 & 2.77 \\
8 & 0.558 & 2.98 \\
7 & 0.532 & 3.00 \\
6 & 0.481 & 3.34 \\
5 & 0.379 & 4.33 \\
\hline
\end{tabular}

Basically, the variation of $n$ is due to the fact that, when $F_{\max }$ is decreased, the very steep initial rise of $F$ at short times takes more and more importance in the fit, which 
causes an increase of $n$. Indeed, a process controlled by diffusion is characterized by a very fast (theoretically infinitely fast) initial variation of the uptake vs. time because $F \propto t^{1 / 2}$, which is described by high values of $n$ (theoretically $n \rightarrow+\infty$ ) when $t$ is small $(t \rightarrow 0)$ in Eq. 10 .

Figure 12 shows the result of fits in the case of $87.2 \mathrm{mg} / \mathrm{L}$ initial concentration in ref. [51] for which the optimum order takes the higher value, $n=2.45$. It is seen in this figure that the fit with $\mathrm{K} 2$ (dashed line, $R_{2}^{2}=0.976, \mathrm{AARD}_{F} 2=17.3 \%$ ) is much better than with $\mathrm{K} 1$ (solid line, $R_{1}^{2}=0.889, \mathrm{AARD}_{F} 1=29.5 \%$ ) and slightly worse than the fit with Kn (dotted line). The coefficient of determination is only a little smaller for K2 than for Kn (0.976 vs. 0.982, respectively). This fact is confirmed in Figure 12 which demonstrates that the fit with $\mathrm{Kn}$ is a bit better than with $\mathrm{K} 2$ except for the last two points. $\mathrm{K} 2$ gives a better fit than $\mathrm{K} 1$ because the resulting $\mathrm{K} 2$ plot has a faster initial rise and a stronger curvature. However, although $R_{2}^{2}=0.976$ for these data, the fit with K2 should be rejected because the residues are not satisfactory. It may be also noticed in this figure that the discrepancy between the experimental data and the fits is large in the first moments of the process. For the first experimental point, at $t=6 \mathrm{~min}$, the fitting curves with K2 and Kn are too low by ca. $70 \%$. The large residues at short times are the reason for the rather large AARD's reported in Table 5. Again, they are caused by the very fast initial rise of the uptake.

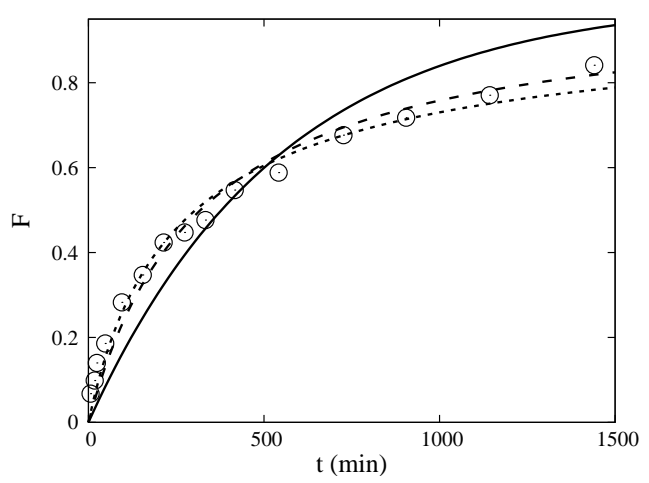

Figure 12: Diffusion-controlled process: data from ref. [51] at $87.2 \mathrm{mg} / \mathrm{L}$ initial concentration. $(\odot)=$ experimental data; solid line = fit with K1 (Eq. 4); dashed line = fit with K2 (Eq. 4); dotted line= fit with Kn (Eq. 10).

The results for the data of ref. [51] at the other concentrations showed the same features as at $87.2 \mathrm{mg} / \mathrm{L}$ initial concentration. As seen in Table 5 the fits with K2 at 35.4 $\mathrm{mg} / \mathrm{L}, 60.3 \mathrm{mg} / \mathrm{L}$ and $131 \mathrm{mg} / \mathrm{L}$ are closely as good as with $\mathrm{Kn}$. However, the very steep initial variation of experimental data is not well represented by any of the rate laws (not shown). Furthermore, the unsatisfactory variation of the residues in the fits of these data with K2 would lead to reject this rate law (if the mechanism was unknown).

The data of ref. [52] give better fits with K2 than with $\mathrm{K} 1$ (higher $R^{2}$ values) but plots of the results show unsatisfactory residues for every solute concentration. Moreover, the value of $R_{2}^{2}$ decreases when the concentration increases, or when $F_{\max }$ decreases.

The main results of this section are as follows. A diffusion controlled process cannot be described really well by $\mathrm{K} 2$ when $F_{\max }$ is of the order of 0.85 , even though the optimum value of the apparent rate order $n$ is close to 2 in this case. When $F_{\max }$ decreases the order $n$ increases strongly and the description with $\mathrm{K} 2$ worsens notably. The rate equations $\mathrm{K} 2$ 
or Kn cannot capture the rapid variation of the uptake at short times.

\subsubsection{Remarks about mechanism}

As has been already underlined in the literature [7,54], the ability of a formula to fit experimental data as a function of time is not sufficient to validate the underlying mechanism. In the present context, a good fit by any of the two chemical rate laws K1 or K2 does not ensure that the kinetics are actually controlled by the adsorption step itself. As a matter of fact, the many studies reporting that pseudo-second order kinetics fitted their data well did not conclude in general that the adsorption step actually controlled the process. Sometimes, results were observed to be described satisfactorily by this rate law and, at the same time, diffusion (in the external layer and/or within the particle) was found to significantly contribute [50]. In other cases, diffusion has been proposed as the rate-controlling process $[5,6,55,56]$.

In this work, it has been found in sections 3.3.2 and 3.3.3 that K1 and K2 were not able to describe some data well. However, at the same time, K2 gave significantly better results than K1. It is interesting to notice that in these cases the uptake exhibited a fast initial increase followed by a leveling off. An example of this behavior is provided by Figure 10. It was also observed more markedly in the case of the data of ref. [40] (not shown). This type of profile may suggest a process in which a fast initial step limited by diffusion is followed by a slower second step (limited by diffusion in smaller pores, or by a slow adsorption [7]). According to the preceding section, this behavior may be expected to be better, although not quite well, described by K2 than by K1.

\section{Conclusion}

The comparison of pseudo-first order and pseudo-second order rate laws for the description of adsorption kinetics has been reexamined.

It appears that, in the literature, the inclusion of data close to, or at, equilibrium to determine the best kinetic formula is not logical, and it has introduced a methodological bias. This bias has widely and unfairly promoted pseudo-second order kinetics as the number one model. The upper fractional uptake should be limited to a value below 1 in order to take into account data sufficiently far from equilibrium. In this work, data for which the fractional uptake was lower than $85 \%$ have been considered.

Moreover, it must be underlined that there is a statistical issue in the usual method employed in the literature. Namely, the two rate laws must be compared for their abilities to represent the same quantity, namely the capacity $q$ or the fractional uptake $F$. This condition requires the use of nonlinear regression and statistics for comparison of the rate equations. In this study, K1 or K2 was declared the best rate law provided it gave the higher coefficient of determination $\left(R^{2}\right)$, together with the condition $R^{2}>0.8$ [19]. However, because the value of $R^{2}$ is not a sufficient criterion [19, 30], the residues resulting from a fit moreover needed to exhibit a random behavior around zero as a function of time.

If one examines literature data the along these lines, one gets a significantly different picture in which the pseudo-first order and pseudo-second order rate equations now perform nearly equally well. Overall in this study, out of a total of 48 data sets, K1 and K2 gave better fits in $\sim 33 \%$ and $35 \%$ of the cases, respectively. Neither rate equation was satisfactory in $\sim 31 \%$ of the cases. In the latter case, K2 performed generally better than $\mathrm{K} 1$. 
It has been found that a diffusion-controlled process is better described by K2 than by K1. However it seems that K2 cannot quite well account for such a process because it is unable to represent the steep rise of the uptake at short times.

In the present work, a difficulty met in the statistical analysis of published data was that the number of experimental points for a given system was sometimes not large. In this respect, it may be suggested to collect as many data as possible in order to better characterize the transient profile of the uptake. This would allow one to get a more statistically significant treatment of the results. Furthermore, it would be useful to have a precise estimation of the uncertainty for every data point collected in an experiment. This additional information would permit to quantitatively estimate the statistical significance of a rate equation through the computation of the so-called P-value [57]. This estimator may serve to assess how well a rate equation fits the data, and therefore to adopt or reject this equation. Let us note that the P-value can be computed easily with various softwares, for instance by utilizing the plotting program Gnuplot (free software).

Lastly, at the experimental level, it should not be forgotten that the simple study of the effect of the adsorbent particle size can provide useful information about the limiting phenomenon. Thus a clear dependence of the kinetics on the particle size points to the influence of diffusion on the rate without ambiguity [1].

In the future, we should try to gain more insight into the kinetics of solute adsorption at the liquid/solid interface itself. In subsequent work, it will be attempted to probe this elementary step in typical adsorbents.

\section{Acknowledgments}

Useful discussions with Agnès Bée, A. Di Bucchianico and O. Lopez are acknowledged.

\section{References}

[1] G. E. Boyd, A. W. Adamson, L. S. Myers, The exchange adsorption of ions from aqueous solutions by organic zeolites. II. Kinetics, J. Am. Chem. Soc. 69 (1947) 2836-2848.

[2] W. Weber, J. Morris, Kinetics of adsorption on carbon from solutions, J. Sanit. Eng. Div. Am. Soc. Civ. Eng. 89 (1963) 31-60.

[3] W. Rudzinski, W. Plazinski, Theoretical description of the kinetics of solute adsorption at heterogeneous solid/solution interfaces: On the possibility of distinguishing between the diffusional and the surface reaction kinetics models, Appl. Surf. Sci. 253 (2007) 5827-5840.

[4] A. Chatterjee, S. Schiewer, Multi-resistance kinetic models for biosorption of Cd by raw and immobilized citrus peels in batch and packed-bed columns, Chem. Eng. J. 244 (2014) 105-116.

[5] J.-P. Simonin, J. Bouté, Intraparticle diffusion-adsorption model to describe liquid/solid adsorption kinetics, Rev. Mex. Ing. Quim. 15 (2016) 161-173.

[6] V. Russo, R. Tesser, D. Masiello, M. Trifuoggi, M. Di Serio, Further verification of adsorption dynamic intraparticle model (ADIM) for fluid-solid adsorption kinetics in batch reactors, Chem. Eng. J. 283 (2016) 1197-1202. 
[7] J. J. Pignatello, B. Xing, Mechanisms of slow sorption of organic chemicals to natural particles, Environ. Sci. Technol. 30 (1995) 1-11.

[8] S. Y. Lagergren, Zur Theorie der sogenannten Adsorption gelöster Stoffe, Kungliga Svenska Vetenskapsakad. Handlingar 24 (1898) 1-39.

[9] G. Blanchard, M. Maunaye, G. Martin, Removal of heavy metals from waters by means of natural zeolites, Water Res. 18 (1984) 1501-1507.

[10] T. Gosset, J.-L. Trancart, D. R. Thévenot, Batch metal removal by peat. Kinetics and thermodynamics, Water Res. 20 (1986) 21-26.

[11] Y. Ho, G. McKay, Pseudo-second order model for sorption processes, Process Biochem. 34 (1999) 451-465.

[12] Y.-S. Ho, Review of second-order models for adsorption systems, J. Hazard. Mater. 136 (2006) 681-689.

[13] S. Khare, K. Panday, R. Srivastava, V. Singh, Removal of victoria blue from aqueous solution by fly ash, J. Chem. Technol. Biotechnol. 38 (1987) 99-104.

[14] G. Gupta, G. Prasad, K. Panday, V. Singh, Removal of chrome dye from aqueous solutions by fly ash, Wat. Air Soil Pollut. 37 (1988) 13-24.

[15] M.-S. Chiou, H.-Y. Li, Equilibrium and kinetic modeling of adsorption of reactive dye on cross-linked chitosan beads, J. Hazard. Mater. 93 (2002) 233-248.

[16] I. D. Mall, V. C. Srivastava, N. K. Agarwal, I. M. Mishra, Adsorptive removal of malachite green dye from aqueous solution by bagasse fly ash and activated carbonkinetic study and equilibrium isotherm analyses, Colloids Surf. A: Physicochem. Eng. Aspects 264 (2005) 17-28.

[17] A. Hosseini-Bandegharaei, M. S. Hosseini, M. Sarw-Ghadi, S. Zowghi, E. Hosseini, H. Hosseini-Bandegharaei, Kinetics, equilibrium and thermodynamic study of $\mathrm{Cr}(\mathrm{VI})$ sorption into toluidine blue o-impregnated XAD-7 resin beads and its application for the treatment of wastewaters containing Cr(VI), Chem. Eng. J. 160 (2010) 190-198.

[18] A. Pal, S. Pan, S. Saha, Synergistically improved adsorption of anionic surfactant and crystal violet on chitosan hydrogel beads, Chem. Eng. J. 217 (2013) 426-434.

[19] A. Di Bucchianico, Coefficient of determination $\left(\mathrm{R}^{2}\right)$, in: Encyclopedia of Statistics in Quality and Reliability, Wiley Online Library, 2008.

[20] T. O. Kvålseth, Cautionary note about R², Am. Stat. 39 (1985) 279-285.

[21] A. Scott, C. Wild, Transformations and R², Am. Stat. 45 (1991) 127-129.

[22] A. Jumasiah, T. Chuah, J. Gimbon, T. Choong, I. Azni, Adsorption of basic dye onto palm kernel shell activated carbon: sorption equilibrium and kinetics studies, Desalination 186 (2005) 57-64.

[23] V. C. Srivastava, I. D. Mall, I. M. Mishra, Characterization of mesoporous rice husk ash (RHA) and adsorption kinetics of metal ions from aqueous solution onto RHA, J. Hazard. Mater. 134 (2006) 257-267. 
[24] B. Hameed, A. Din, A. Ahmad, Adsorption of methylene blue onto bamboo-based activated carbon: Kinetics and equilibrium studies, J. Hazard. Mater. 141 (2007) 819-825.

[25] H. K. Boparai, M. Joseph, D. M. O'Carroll, Kinetics and thermodynamics of cadmium ion removal by adsorption onto nano zerovalent iron particles, J. Hazard. Mater. 186 (2011) 458-465.

[26] J. P. Kushwaha, V. C. Srivastava, I. D. Mall, Treatment of dairy wastewater by commercial activated carbon and bagasse fly ash: Parametric, kinetic and equilibrium modelling, disposal studies, Bioresource Technol. 101 (2010) 3474-3483.

[27] M. A. Tofighy, T. Mohammadi, Adsorption of divalent heavy metal ions from water using carbon nanotube sheets, J. Hazard. Mater. 185 (2011) 140-147.

[28] R. Anderson-Sprecher, Model comparisons and R², Am. Stat. 48 (1994) 113-117.

[29] V. J. Vilar, C. M. Botelho, R. A. Boaventura, Kinetics and equilibrium modelling of lead uptake by algae gelidium and algal waste from agar extraction industry, J. Hazard. Mater. 143 (2007) 396-408.

[30] W. Guthrie, Engineering Statistics Handbook, Section 4.4 Model validation, http://www.itl.nist.gov/div898/handbook/index.htm, NIST/SEMATECH (2013).

[31] Y. Ho, D. Wase, C. Forster, The adsorption of divalent copper ions from aqueous solutions by sphagnum peat., Trans. IChemE 17 (1994) 185-194.

[32] B. K. Singh, N. S. Rawat, Comparative sorption kinetic studies of phenolic compounds on fly ash and impregnated fly ash, J. Chem. Technol. Biotechnol. 61 (1994) $57-65$.

[33] A. Kaur, A. Malik, N. Verma, A. Rao, Removal of copper and lead from wastewater by adsorption on bottom ash, Indian J. Environ. Prot. 11 (1991) 433-435.

[34] R. Salim, M. Al-Subu, E. Sahrhage, Uptake of cadmium from water by beech leaves, J. Environ. Sci. Health A 27 (1992) 603-627.

[35] M. Bhutani, R. Kumari, Adsorption of low level ${ }^{51} \mathrm{Cr}(\mathrm{VI})$ from aqueous solution by bismuth trioxide: Kinetic and IR study, J. Radioanal. Nucl. Chem. 180 (1994) $145-153$.

[36] Y. Sharma, G. Gupta, G. Prasad, D. Rupainwar, Use of wollastonite in the removal of Ni(II) from aqueous solutions, Water Air Soil Poll. 49 (1990) 69-79.

[37] K. Periasamy, C. Namasivayam, Removal of copper(II) by adsorption onto peanut hull carbon from water and copper plating industry wastewater, Chemosphere 32 (1996) 769-789.

[38] R. Salim, M. Al-Subu, S. Qashoa, Removal of lead from polluted water using decaying leaves, J. Environ. Sci. Health A 29 (1994) 22087-2114. 
[39] D. Bhargava, S. Sheldarkar, Use of TNSAC in phosphate adsorption studies and relationships. Literature, experimental methodology, justification and effects of process variables, Wat. Res. 27 (1993) 303-312.

[40] O. Sayrafi, R. Salim, S. Sayrafi, Removal of cadmium from polluted water using decaying leaveseffects of type of leaves and of concentration of cadmium, J. Environ. Sci. Health A 31 (1996) 2503-2513.

[41] Y. Chanie, I. Díaz, E. Pérez, Kinetics and mechanisms of adsorption/desorption of the ionic liquid 1-buthyl-3-methylimidazolium bromide into mordenite, J. Chem. Technol. Biotechnol. 91 (2015) 705-710.

[42] X. Han, L. Chu, S. Liu, T. Chen, C. Ding, J. Yan, L. Cui, G. Quan, Removal of methylene blue from aqueous solution using porous biochar obtained by $\mathrm{KOH}$ activation of peanut shell biochar, BioResources 10 (2015) 2836-2849.

[43] S. U. Lee, Y.-S. Jun, E. Z. Lee, N. S. Heo, W. H. Hong, Y. S. Huh, Y. K. Chang, Selective silver ion adsorption onto mesoporous graphitic carbon nitride, Carbon 95 (2015) 58-64.

[44] B. Zhu, P. Xia, W. Ho, J. Yu, Isoelectric point and adsorption activity of porous g- $\mathrm{C}_{3} \mathrm{~N}_{4}$, Applied Surf. Sci. 344 (2015) 188-195.

[45] M. Dastkhoon, M. Ghaedi, A. Asfaram, A. Goudarzi, S. M. Langroodi, I. Tyagi, S. Agarwal, V. K. Gupta, Ultrasound assisted adsorption of malachite green dye onto ZnS: Cu-NP-AC: Equilibrium isotherms and kinetic studies-response surface optimization, Sep. Purif. Technol. 156 (2015) 780-788.

[46] M. Maghsoudi, M. Ghaedi, A. Zinali, A. Ghaedi, M. Habibi, Artificial neural network (ANN) method for modeling of sunset yellow dye adsorption using zinc oxide nanorods loaded on activated carbon: Kinetic and isotherm study, Spectrochim. Acta Part A 134 (2015) 1-9.

[47] A. Benhouria, M. A. Islam, H. Zaghouane-Boudiaf, M. Boutahala, B. Hameed, Calcium alginate-bentonite-activated carbon composite beads as highly effective adsorbent for methylene blue, Chem. Eng. J. 270 (2015) 621-630.

[48] N. Caner, A. Sari, M. Tüzen, Adsorption characteristics of mercury(II) ions from aqueous solution onto chitosan-coated diatomite, Ind. Eng. Chem. Res. 54 (2015) $7524-7533$.

[49] T. E. Dudu, M. Sahiner, D. Alpaslan, S. Demirci, N. Aktas, Removal of $\mathrm{As}(\mathrm{V})$, Cr(III) and $\mathrm{Cr}(\mathrm{VI})$ from aqueous environments by poly(acrylonitrilco-acrylamidopropyl-trimethyl ammonium chloride)-based hydrogels, J. Environ. Manag. 161 (2015) 243-251.

[50] S. He, C. Han, H. Wang, W. Zhu, S. He, D. He, Y. Luo, Uptake of $\operatorname{arsenic(V)}$ using alumina functionalized highly ordered mesoporous SBA-15 (Al x-SBA-15) as an effective adsorbent, J. Chem. Eng. Data 60 (2015) 1300-1310.

[51] X.-Y. Yang, B. Al-Duri, Application of branched pore diffusion model in the adsorption of reactive dyes on activated carbon, Chem. Eng. J. 83 (2001) 15-23. 
[52] K. K. Choy, J. F. Porter, G. McKay, Intraparticle diffusion in single and multicomponent acid dye adsorption from wastewater onto carbon, Chem. Eng. J. 103 (2004) $133-145$.

[53] J. Crank, The Mathematics of Diffusion, Clarendon Press, Oxford (GB), 1975.

[54] H. Qiu, L. Lv, B.-C. Pan, Q.-J. Zhang, W.-M. Zhang, Q.-X. Zhang, Critical review in adsorption kinetic models, J. Zhejiang Univ. Sci. A 10 (2009) 716-724.

[55] J. W. McBain, Theories of occlusion and the sorption of iodine by carbon, Trans. Faraday Soc. 14 (1919) 202-212.

[56] D. Do, Adsorption Analysis: Equilibria and Kinetics, Chemical Engineer Series, Volume 2, Imperial College Press, 1998.

[57] R. L. Ott, M. Longnecker, An introduction to statistical methods and data analysis, Cengage Learning, Boston, USA, 2008. 